\title{
Surface properties and exopolysaccharide production of surface-associated microorganisms isolated from a dairy plant
}

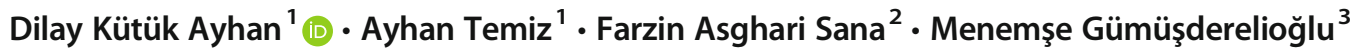

Received: 8 January 2019 / Accepted: 14 May 2019 / Published online: 23 May 2019

(C) Università degli studi di Milano 2019

\begin{abstract}
Purpose The purpose of this study was to isolate the surface-associated microorganisms from the dairy plant surfaces with a high probability of biofilm formation and determine the most adhesive strains in terms of surface properties and exopolysaccharide production.

Methods Four hundred and ninety-five surface-associated microorganisms were isolated from potential biofilm-forming surfaces of a dairy plant. One hundred and seventy of these were isolated after cleaning/disinfection of the pasteurized milk, white cheese and butter tank, yogurt and ice cream filling unit, ice cream air pressing, and condensed milk pipe. It is noteworthy that some isolates might cause post-production contamination, food infection, and intoxication. Selected 42 isolates were identified by Gram staining, physiological and biochemical tests, and 16S rRNA gene sequencing. Then, surface properties and exopolysaccharide production of 10 selected isolates were determined. To evaluate the surface properties, microbial adhesion to hydrocarbons, static water contact angle, salt aggregation, and surface zeta potential tests were performed.

Result The microbial adhesion to hydrocarbons (MATH) test exhibited the lowest standard deviations, and the most consistent results between the replicates. The highest hydrophilic characteristics and exopolysaccharide production were exhibited by Gram-negative Pseudomonas aeruginosa, followed by Gram-positive Bacillus toyonensis. Also, a significant diversity of neutral sugar was determined in their alditol acetate forms by using gas chromatography-mass spectrometry. In this context, it is believed that the determination of the EPS content of the isolates would contribute to establishing an effective cleaning/disinfection procedure for dairy plants.

Conclusion This study indicated that microbial adhesion is still a common problem in the dairy industry. Because of this situation, dairy plants should be organized and constructed to be suitable for hygiene and sanitary applications.
\end{abstract}

Keywords Dairy plant $\cdot$ Adhesion $\cdot$ Identification $\cdot$ Surface property $\cdot$ Exopolysaccharide production $\cdot$ Neutral sugar content

\section{Introduction}

Biofilm is a microbial-derived cell community located in a matrix that contains extracellular polymeric substances, which allows microorganisms to bind irreversibly to living and non-

Dilay Kütük Ayhan

dilaykutuk@hacettepe.edu.tr

1 Department of Food Engineering, Hacettepe University, Beytepe, Ankara, Turkey

2 Department of Nanotechnology \& Nanomedicine, Hacettepe University, Beytepe, Ankara, Turkey

3 Department of Chemical Engineering, Hacettepe University, Beytepe, Ankara, Turkey living surfaces or irreversibly to each other. Microorganisms in biofilms have a different phenotype in terms of their reproductive rate and gene transcription profile compared with planktonic types (Donlan and Costerton 2002). These microorganisms are typically more virulent, more easily adaptable to changing environmental factors, and are able to develop resistance to antibiotics (Watnick and Kolter 2000).

Numerous examples of the microorganisms are isolated from dairy plants in literature (Cherif-Antar et al. 2016; Soares et al. 2011). The microorganisms, separated from the surfaces by various methods, are then isolated and counted by cultural methods following inoculation into selective and/or non-selective media. Various methods can be used for the isolation of biofilm-forming microorganisms from surfaces. These methods include the use of swabs (Marques et al. 2007; Valeriano et al. 2012), humidified swabs (Lortal et al. 
2009; Waines et al. 2011), gauze (Tang et al. 2011), scraping (Frank and Koffi 1990), sponges (Knight and Craven 2010), sonication and centrifugation (Bjerkan et al. 2009; Kajiyama et al. 2009), surface washing, immersion in a washing solution, agar sausage (Harrigan 1998), cutting (Lortal et al. 2009), and vortexing (Mustapha and Liewen 1989).

Identification of the microorganisms is generally carried out by morphological, physiological, and biochemical tests. Biochemical tests usually include API test kits (BioMérieux, France) (Bağc1 2012; Brolazo et al. 2011; Palmer et al. 2010). Traditional microbiological techniques require a long time and a lot of chemicals, media, and labor. However, these techniques may also be insufficient for identifying species when used alone. In addition to these tests, microorganisms can be identified by molecular microbiological techniques such as determination of DNA base composition (using PCR techniques), DNA hybridization tests, FISH (fluorescence in situ hybridization), and 16S rRNA gene sequencing (Palmer et al. 2010; Waines et al. 2011).

The surface properties of microorganisms are important factors in the mechanisms of adhesion. The term macroscopic hydrophobicity refers to the wettability of a surface in an air environment (Ukuku and Fett 2002). Microbial hydrophobicity is an important factor that affects adhesion to a surface, i.e., biofilm formation. Microbial hydrophobicity can be determined by methods such as microbial adhesion to hydrocarbon test or through hydrophobic interaction chromatography (Rijnaarts et al. 1995).

Studies have shown that both adherence-cohesion interactions on a surface and the ability of the microorganisms to produce extracellular polymeric substances (EPS) are important for adhesion (Chen and Stewart 2002; Drenkard 2003). It has also been shown that EPS production is a precondition for supporting the formation of biofilms on surfaces and enhancing adhesion. Therefore, it is of great importance to understand the ability of surface-adhering microorganisms to produce EPS and to understand the content of EPS they produce.

The aim of this study was first to determine the surfaces having a potential risk of biofilm formation in dairy plants. For this purpose, microorganisms were isolated from a dairy plant in Ankara. Isolation was applied from the surfaces with a high probability of biofilm formation by using general and selective media. The selected isolates were identified by morphological, physiological, and biochemical tests and 16S rRNA gene sequencing. The selected isolates were evaluated based on their ability to produce EPS and their morphological structure. The surface properties of the microorganisms were assessed using the microbial adhesion to hydrocarbons (MATH) test, the static water contact angle test, the salt aggregation test, and the surface zeta potential test. EPS were isolated from microorganisms and their total sugar, uronic acid, and neutral sugar contents were determined.

\section{Materials and methods}

\section{Isolation and identification of microorganisms from a dairy plant}

Microbiological samples were taken from 13 sampling points from a dairy plant in Ankara, Turkey, in order to isolate surface-associated microorganisms. The sampling points were: (1) raw milk tank, (2) pasteurized milk tank, (3) starter tank, (4) yogurt-filling unit (350 g), (5) yogurt filling unit (1500 g), (6) white cheese tank, (7) white cheese-pressing cloth, (8) kashar maturing bench, (9) old kashar maturing bench, wood, (10) butter tank, (11) ice cream filling unit, (12) ice cream air pressing pipe, and (13) condensed milk pipe. Sampling was generally repeated twice, before and after the cleaning/disinfection step. Samples were assigned a twodigit code, the first digit indicating the sampling point, and the second digit indicating whether sanitation has been applied or not, with 1 and 2 representing that the sample was taken either before or after the sanitation step, respectively.

Microbiological sampling was carried out by rubbing a moistened swab (with $0.1 \%$ buffered peptone water) strongly in different directions on the sampling surface. The swabs were then immersed in tubes containing $2 \mathrm{~mL}$ of Tryptic Soy Broth (TSB, Sigma-Aldrich), and the tubes were vortexed for 2 min to allow the passage of microorganisms into the broth (Marques et al. 2007; Valeriano et al. 2012; Waines et al. 2011).

The agar media and incubation temperatures used for the isolation of microorganisms are shown in Table 1.

Microbiological cultivation was carried out using the spread plate technique as two replicates (Harrigan 1998; Temiz 2010). Inoculated Petri dishes were incubated at the optimum growth temperature of the target microorganisms (Table 1). The incubation times were $24-48 \mathrm{~h}$ for the bacteria and $24-96 \mathrm{~h}$ for the yeasts. After incubation, the colonies developed on the agar media were examined to assess their morphological characteristics, and colonies showing different morphological characteristics were selected and their pure cultures were obtained. In order to obtain pure cultures, the individual colonies firstly re-streaked onto the same selective media which they were isolated from, and then the colonies which were grown on the selective media were re-streaked onto the nutrient agar (Merck) plates. Isolated pure cultures were maintained as stock cultures at $-80{ }^{\circ} \mathrm{C}$ in a brain heart infusion (BHI, Merck) broth medium containing $20 \%$ glycerol $(v / v)$ for further analysis. Intermediate stock cultures were prepared using nutrient agar slant from the stock cultures, and they were stored in a refrigerator at $0-5{ }^{\circ} \mathrm{C}$ with regenerating every 3 months. From these intermediate stock cultures, 24-h cultures were obtained in a nutrient broth (Merck) medium and they were used for further analysis. 
Table 1 The agar media and incubation temperatures used for the isolation of the target microorganisms

\begin{tabular}{|c|c|c|}
\hline The agar media & $\begin{array}{l}\text { Target } \\
\text { microorganisms }\end{array}$ & $\begin{array}{l}\text { Incubation } \\
\text { temperature }\left({ }^{\circ} \mathrm{C}\right)\end{array}$ \\
\hline Violet red bile dextrose agar (VRBDA, Merck) & Enterobacteriaceae members & $37 \pm 1$ \\
\hline Fluorocult violet red bile agar (Merck) & E. coli & $37 \pm 1$ \\
\hline Baird parker agar (BPA, Oxoid) & Staphylococcus spp. & $37 \pm 1$ \\
\hline $\begin{array}{l}\text { Pseudomonas agar base (PA, Sigma-Aldrich) with CFC } \\
\text { (cetrimide, fucidin, cephalosporin) supplement }\end{array}$ & Pseudomonas spp. & $37 \pm 1$ \\
\hline $\begin{array}{l}\text { Lactobacillus agar acc. to De Man, Rogosa and Sharpe } \\
\text { (MRS agar, Sigma-Aldrich) }\end{array}$ & Lactobacillus spp. & $30 \pm 1$ \\
\hline M17 agar (Oxoid) & Lactococcus spp. & $37 \pm 1$ \\
\hline Chromogenic Listeria agar (OCLA, Oxoid) & Listeria spp. & $37 \pm 1$ \\
\hline Dextrose casein-peptone agar (DCPA, Merck) & Bacillus spp. & $37 \pm 1$ \\
\hline $\begin{array}{l}\text { Brilliant green phenol red lactose sucrose agar } \\
\text { (BPLS Agar, Merck) }\end{array}$ & Salmonella spp. & $37 \pm 1$ \\
\hline Yeast extract agar (YEA, Sigma-Aldrich) & Yeasts & $30 \pm 1$ \\
\hline
\end{tabular}

The microscopic morphology of each pure culture was determined and an API test kit (bioMérieux, France) was used to identify them at the species level. The API test kits used were as follows: API 20 E for Enterobacteriaceae members; API 20 NE for Pseudomonas spp.; API Staph for Staphylococcus spp.; API Listeria for Listeria spp.; API 50CHB for Bacillus spp.; API 50CHL for Lactobacillus spp.; API Strep for Lactococcus spp.; and API 20C AUX for yeasts.

API test kits do not always give consistent results for the identification of lactic acid bacteria (Brolazo et al. 2011; Martín et al. 2010). To ensure the discrimination of lactic acid bacteria, some basic morphological, physiological, and biochemical tests (Gram staining, catalase activity, gas production from growth in glucose, growth at $10{ }^{\circ} \mathrm{C}$ and $45{ }^{\circ} \mathrm{C}$, growth in $2 \%, 4 \%$, and $6 \%$ saltcontaining media, growth at $\mathrm{pH} 9.6$, arginine hydrolysis, and an hemolysis test) were also used to assess suspected isolates of lactic acid bacteria from the MRS agar and M17 agar media.

To identify pure cultures at the species level, the isolates were also subjected to $16 \mathrm{~S}$ rRNA gene sequencing using universal primers (Sanger et al. 1977). DNA extraction was performed using Qiagen DNeasy Blood \& Tissue Kit (Qiagen Inc., Valencia, CA). The $16 \mathrm{~S}$ rRNA genes were amplified using the primer pairs of $27 \mathrm{~F}$ (5'-AGA GTT TGA TCC TGG CTC AG) and 907R (5'-CCC CGT CAA TTC ATT TGA GTT T). The PCR mix $(50 \mu \mathrm{L})$ was prepared from $1 \mu \mathrm{L}$ dNTP, $5 \mu \mathrm{L} 10 \times$ buffer, $0.3 \mu \mathrm{L} 27 \mathrm{~F}$ primer, $0.3 \mu \mathrm{L}$ 907R primer, $0.3 \mu \mathrm{L}$ Taq polymerase (Boehringer $\mathrm{GmbH}$, Mannheim, Germany), and $2 \mu \mathrm{L} \mathrm{MgCl}_{2}$. Five hundred nanograms of DNA extract was amplified with the PCR mix. Polymerase chain reaction amplification was performed with the following thermal conditions: $94{ }^{\circ} \mathrm{C}$ for a 2-min step, 30 cycles of $94{ }^{\circ} \mathrm{C}$ for $30 \mathrm{~s}, 58^{\circ} \mathrm{C}$ for $30 \mathrm{~s}, 72{ }^{\circ} \mathrm{C}$ for $30 \mathrm{~s}$, and finished by a $72{ }^{\circ} \mathrm{C}$ for a 5 -min step. PCR purification was applied with Promega PCR Purification kit (Promega,
Madison, WI, USA). Sequence results were evaluated using the NCBI BLAST program.

\section{Surface properties of microorganisms}

Microbial adhesion to hydrocarbons, static water contact angle, salt aggregation, and surface zeta potential test measurements were performed in triplicate as described below.

\section{Microbial adhesion to hydrocarbons test}

The cell surface hydrophobicity of the identified microorganisms was determined using the microbial adhesion to hydrocarbons test and reported as \% $\mathrm{H}$. The absorbance values of 24-h cell cultures before and after the application of n-decane (BDH Chemicals, UK) were measured at $400 \mathrm{~nm}$ using a spectrophotometer (Thermo Scientific, iCE 3000 Series Atomic Absorption Spectrometers, USA) (Rosenberg et al. 1980). In this method, the absorbance value before the n-decane application $\left(A_{0}\right)$ was firstly measured by the spectrophotometer. Then $1 \mathrm{~mL}$ of $\mathrm{n}$-decane was added onto $3 \mathrm{~mL}$ culture suspension. The suspension was then vortexed for $2 \mathrm{~min}$ and allowed to stand for $15 \mathrm{~min}$ to remove the hydrocarbon. The absorbance value after the n-decane application $(A)$ was measured by the spectrophotometer from the underlying phase of the two-phase mixture. Surface hydrophobicity $(\% \mathrm{H})$ was determined using the following formula.

$\% \mathrm{H}=\left[\left(\mathrm{A}_{0}-\mathrm{A}\right) / \mathrm{A}_{0}\right] \times 100$

$A_{0} \quad$ The absorbance value before the n-decane application

$A$ The absorbance value after the n-decane application 


\section{Static water contact angle test}

The static water contact angle values of the identified microorganisms were determined using the sessile drop method described by Absolom et al. (1983). Three replicates were studied for each measurement using a goniometer (Krüss DSA 100, Germany) at room temperature.

\section{Salt aggregation test}

Eighty microliters $24-\mathrm{h}$ culture was transferred to $80 \mu \mathrm{L}$ ammonium sulphate solution at different concentrations (between 0.01 and $4 \mathrm{M}$ ) in each well of a cavity slide. Crystal violet was added to make the agglutinates visible. The salt aggregation test (SAT) value was obtained by observing the lowest concentration of ammonium sulfate that produces visible agglutinates (Styriak et al. 1999).

\section{Surface zeta potential test}

Before measurements, the 24-h cultures (viable cell number: $1.5 \times 10^{8} \mathrm{CFU} / \mathrm{mL}$ ) of test microorganisms were prepared. Measurements were then made using a Zetasizer (3000HSA, Malvern Instruments, UK).

\section{Isolation of exopolysaccharides}

The microorganism was inoculated into $10 \mathrm{~mL}$ of sterile skimmed milk, and incubated at $37^{\circ} \mathrm{C}$ for $24 \mathrm{~h}$. One milliliter of $4 \%$ trichloroacetic acid $(v / v)$ was then added to each culture to precipitate proteins and cells, and the mixture was incubated in a shaking water bath at $37{ }^{\circ} \mathrm{C}$ for $2 \mathrm{~h}$. The suspension was centrifuged for $35 \mathrm{~min}$ at $10,000 \times \mathrm{g}$ at $4{ }^{\circ} \mathrm{C}$, and the supernatant was separated and filtered through a $0.45-\mu \mathrm{m}$ membrane filter (Millipore, USA). Following this, $96 \%$ cold ethyl alcohol $(v / v)$ was added to the supernatant at ratios of $1: 1,1: 2$, and $1: 3$ followed by centrifugation at $5000 \times g$ for $15 \mathrm{~min}$ at $4{ }^{\circ} \mathrm{C}$ after each treatment. The resulting EPS were dissolved in $1 \mathrm{~mL}$ of water and filtered through a $0.45-\mu \mathrm{m}$ membrane filter. Finally, the EPS were obtained in dry form by lyophilization using a freeze dryer (ALPHA 1-4 LDplus, Christ, Germany) (Yang 2000).

\section{Determination of total sugar}

The total sugar was determined spectrophotometrically using the phenol sulfuric acid method described by DuBois et al. (1956).

\section{Determination of uronic acid}

The uronic acid content of the isolated EPS was determined spectrophotometrically following conversion to galactonic acid (Blumenkrantz and Asboe-Hansen 1973).

\section{Determination of neutral sugar}

The neutral sugars predominant in the EPS derived from each microorganism were identified using GC-MS. EPS (10$100 \mu \mathrm{g}$ ) were first treated with $0.5 \mathrm{~N} \mathrm{NH}_{4} \mathrm{OH}$ solution $(100 \mu \mathrm{L})$ and incubated at room temperature for 10-15 $\mathrm{min}$ in a closed tube. Next, $1 \mathrm{mg}$ of $\mathrm{NaBH}_{4}$ was added and the solution was kept closed for $10 \mathrm{~min}$ at $100{ }^{\circ} \mathrm{C}$. At this stage, aldoses are reduced to alditols. The tube contents were dried at $55^{\circ} \mathrm{C}$. Excess $\mathrm{NaBH}_{4}$ was cleaved by the addition of $100 \mu \mathrm{L}$ of $2 \mathrm{M}$ trifluoroacetic acid. Then, $100 \mu \mathrm{L}$ of methanol was added and the solution was dried at $55{ }^{\circ} \mathrm{C}$ to remove the cleavage products (repeated two times). The residue was dissolved with $0.5 \mathrm{M} \mathrm{HCl}(200 \mu \mathrm{L})$ in methanol, and the solution was kept closed at $100{ }^{\circ} \mathrm{C}$ for $15 \mathrm{~min}$ and dried at $55^{\circ} \mathrm{C}$. During this step, the alditols are derivatized to methyl ester alditol forms. These methyl ester alditols were acetylated by adding a mixture of pyridine-acetonitrile $(200 \mu \mathrm{L} ; 1: 1, v / v)$ and incubated at $100{ }^{\circ} \mathrm{C}$ for $30 \mathrm{~min}$ in a closed tube. The percentage distribution of neutral sugars in the EPS solution isolate was quantitatively determined using GC-MS with a TRACE DSQII (Thermo Fisher Scientific, Waltham, MA, USA) (Sassaki et al. 2008).

The conditions used for the GC-MS analysis were as follows: injector, split mode; injection volume $2 \mu \mathrm{L}$; detector MS DSQII; column: 7HG-G006-11 Zebron ZB-1701 capillary GC column $(30 \mathrm{~m} \times 0.25 \mathrm{~mm} \times 0.25 \mu \mathrm{m}$, Phenomenex $)$; carrier gas: helium $(1 \mathrm{~mL} / \mathrm{min})$; mass range $35-500$; temperature program: $60^{\circ} \mathrm{C}$ for $5 \mathrm{~min}, 60^{\circ} \mathrm{C}-270{ }^{\circ} \mathrm{C}$ at $10^{\circ} \mathrm{C} / \mathrm{min}, 270{ }^{\circ} \mathrm{C}$ for $15 \mathrm{~min}$; ion source temperature: $230^{\circ} \mathrm{C}$; transfer line temperature: $270{ }^{\circ} \mathrm{C}$.

\section{Results}

\section{Isolation and identification of microorganisms from the dairy industry}

Totally, 495 isolates were obtained using the different agar media. Among these, 36 were isolated from VRBDA, 38 from FVRBA, 34 from BPA, 19 from PA, 55 from MRS agar, 78 from M17 agar, 17 from OCLA, 66 from DCPA, 20 from BPLS agar, and 132 from YEA media. Of the 495 colonies isolated, there were 163 typical and 332 atypical colonies. Totally, 170 isolates were obtained after the sanitation steps in the dairy plant. These microorganisms were isolated after the cleaning/disinfection processes of the tanks of pasteurized 
milk, white cheese and butter, the filling units of yogurt and ice cream, and the pipes of ice cream air pressing and condensed milk. Eighty-six out of 170 isolates produced mucous colonies.

The isolated microorganisms were grouped according to diversity in their macroscopic (colony shape and structure, typical or atypical colony formation, etc.) and microscopic morphologies, Gram-staining reactions (for bacteria), physiological and biochemical test results, behavior in the dairy industry (saprophyte or fecal contamination indicator), their pathogenicity, and toxicity. Among these, 42 isolates were selected for identification at the species level using API test kits and 16S sequence analysis. These 42 isolates, identified by API and 16S rRNA gene sequencing, were re-grouped according to diversity in their macroscopic (colony shape and structure, typical or atypical colony formation, etc.) and microscopic morphologies, Gram-staining reaction (for bacteria), the results of physiological and biochemical tests, API tests and 16S rRNA gene sequencing, pathogenicity and toxicity potential, spoilage-forming potential in milk and dairy products, and whether they were microorganisms indicative of fecal contamination. Following this, 10 isolates were selected from 42 isolates considering the isolate re-groups mentioned above and studied further. The identity of these isolates is shown in Table 2 along with their isolation surface, isolate codes, isolation media, and their identity obtained through 16S rRNA gene sequencing at the species level. Some of the microorganisms mentioned in Table 2 were isolated from selective media that are used for the selection of other microorganisms instead of from their own selective media.

API test kits usually produce accurate results when defining many bacterial groups. In this study, the results obtained with the API test kits were found to be consistent with the results obtained with 16S rRNA gene sequencing, but there were differences at the species level. For Staphylococcus species, the identification results obtained using 16S rRNA gene sequencing were more consistent with the API results at the species level compared with the identification of other bacteria and yeasts.

\section{Surface properties of microorganisms}

In these experiments, $S$. aureus ATCC 25923 and E. coli ATCC 25922 strains were used as standard control microorganisms, in addition to the 10 test microorganism isolates.

\section{Microbial adhesion to hydrocarbons test}

The MATH test surface hydrophobicity values of the 10 selected isolates and the controls are shown in Table 3. Among the surface tests, the MATH test exhibited the lowest standard deviations, and the most consistent results between the replicates.

The MATH test is one of the criteria used to evaluate the surface adhesion potential of microorganisms. A value greater than $70 \%$ indicates that a test microorganism is hydrophobic, values from 30 to $70 \%$ indicate it is weakly hydrophobic, and values less than $30 \%$ indicate it is hydrophilic (AbasoloPacheco et al. 2015; Kwaszewska et al. 2006). It is thought that hydrophilic MATH values of microorganisms increase surface adhesion. Besides the microorganisms, surfaces also have hydrophilic or hydrophobic characteristics. In the food industry, stainless steel surfaces are frequently used, and the hydrophilic property of these stainless steel surfaces is an important factor in biofilm formation (Frank 2001).

In general, the surface hydrophobicity values of the test microorganisms were positive. However, some test microorganisms (K. variicola, E. coli, P. mirabilis, and E. coli ATCC 25922) had negative values. In general, the literature reports that the surface hydrophobicity values of microorganisms are positive. It has however also been reported in the literature that some microorganism strains have negative values. For example, the surface hydrophobicity values of $E$. coli strains by using dodecane have been reported as being $-2.0 \%$ and $6.0 \%$ by Saini (2010). This is because some hydrocarbons can
Table 2 Microorganisms selected for further study

\begin{tabular}{lll}
\hline Isolation surface & Isolate code & Identity \\
\hline Condensed milk pipe & YEA 13.2.1 & Enterococcus faecalis \\
Yogurt filling unit, $1500 \mathrm{~g}$ & BPA 5.2.2 & Staphylococcus epidermidis \\
Raw milk tank & M17 1.1.1 & Lactococcus garvieae \\
Condensed milk pipe & M17 13.1.2 & Lactococcus garvieae \\
Yogurt filling unit, $1500 \mathrm{~g}$ & YEA 5.2.6 & Bacillus toyonensis \\
Raw milk tank & FVRBA 1.1.5 & Pseudomonas aeruginosa \\
White cheese pressing cloth & VRBDA 7.1.1 & Escherichia coli \\
White cheese pressing cloth & FVRBA 7.1.2 & Klebsiella variicola \\
Yogurt filling unit, 350 g & MRS 4.2.1 & Candida parapsilosis \\
Raw milk tank & VRBDA 1.1.1 & Proteus mirabilis \\
\hline
\end{tabular}


Table 3 Surface test values of the isolates

\begin{tabular}{|c|c|c|c|c|c|}
\hline Isolate Code & Microorganism & $\begin{array}{l}\text { MATH Test surface } \\
\text { hydrophobicity }(\%)^{*}\end{array}$ & $\begin{array}{l}\text { Static water } \\
\text { contact angle }\left({ }^{\circ}\right)^{*}\end{array}$ & SAT (Molar)* & $\begin{array}{l}\text { Surface Zeta } \\
\text { Potential }(\mathrm{mV})^{*}\end{array}$ \\
\hline FVRBA 1.1.5. & Pseudomonas aeruginosa & $10.6 \pm 0.5^{* *}$ & $26.0 \pm 5.1$ & 2.5 & $-5.9 \pm 4.1 * *$ \\
\hline M17 1.1.1. & Lactococcus garvieae & $25.1 \pm 0.7$ & $0.0 \pm 0.0$ & 1.5 & $-16.9 \pm 3.8$ \\
\hline M17 13.1.2. & Lactococcus garvieae & $29.2 \pm 0.7$ & $12.0 \pm 3.3$ & $<0.01$ & $-15.6 \pm 4.6$ \\
\hline YEA 5.2.6. & Bacillus toyonensis & $30.4 \pm 0.2$ & $33.0 \pm 4.5 * *$ & $3.0 * *$ & $-8.8 \pm 0.2$ \\
\hline YEA 13.2.1. & Enterococcus faecalis & $35.1 \pm 1.1$ & $24.0 \pm 1.9$ & $<0.01$ & $-11.5 \pm 3.0$ \\
\hline MRS 4.2.1. & Candida parapsilosis & $45.7 \pm 0.1$ & $0.0 \pm 0.0$ & 2.0 & $-7.9 \pm 0.7$ \\
\hline BPA 5.2.2. & Staphylococcus epidermidis & $74.4 \pm 0.6$ & $25.0 \pm 7.2$ & $<0.01$ & $-13.1 \pm 4.2$ \\
\hline ATCC 25923 & Staphylococcus aureus & $94.2 \pm 0.2$ & $6.0 \pm 4.5$ & $<0.01$ & $-13.7 \pm 6.0$ \\
\hline FVRBA 7.1.2. & Klebsiella variicola & $-10.6 \pm 0.0$ & $22.0 \pm 2.0$ & 0.4 & $-11.4 \pm 4.8$ \\
\hline ATCC 25922 & Escherichia coli & $-8.9 \pm 0.1$ & $21.0 \pm 3.0$ & $<0.01$ & $-18.4 \pm 1.5$ \\
\hline VRBDA 7.1.1. & Escherichia coli & $-7.5 \pm 0.4$ & $18.0 \pm 7.4$ & 2.5 & $-7.4 \pm 2.3$ \\
\hline VRBDA 1.1.1. & Proteus mirabilis & $-5.9 \pm 0.3$ & $0.0 \pm 0.0$ & 2.5 & $-11.0 \pm 4.4$ \\
\hline
\end{tabular}

*Measurements were performed in triplicate, and results are presented as mean \pm standard deviation

**The best result for each test in terms of adhesion capability

diffuse in water, resulting in a higher final absorbance value (A) than the initial absorbance value $\left(A_{0}\right)$. However, in such cases, evaluation can be made using other different hydrocarbons like octane (Saini 2010).

When the negative values were ignored, P. aeruginosa and both of the L. garvieae isolates were the most hydrophilic microorganisms isolated. These isolates were followed by $B$. toyonensis, which had a relatively lower hydrophilic characteristic. The most hydrophobic isolates were $C$. parapsilosis and S. epidermidis. The control S. aureus ATCC 25923 strain was the most hydrophobic microorganism, giving a $94.2 \pm 0.2 \%$ value, whereas the control E. coli ATCC 25922 strain gave the most negative surface hydrophobicity value.

Surface property values may vary strain to strain. On the other hand, the MATH values obtained for the tested microorganisms are generally consistent with the results reported in the literature for the same species (Hamadi and Latrache 2008; $\mathrm{Li}$ and McLandsborough 1999; Minagi et al. 1986). Since information about the MATH values for $L$. garvieae and $B$. toyonensis is not available in the literature, the MATH values for L. garvieae and B. toyonensis were compared with those of L. lactis and B. subtilis, respectively. In the literature, the MATH value for L. lactis was reported as $34.0 \%$ (Marín et al. 1997), whereas the MATH value for B. subtilis was reported as 28.0\% (Abasolo-Pacheco et al. 2015).

Surface hydrophobicity values of the microorganisms vary greatly depending on the strain. For example, the surface hydrophobicity values of the $P$. aeruginosa strains were reported to lie within the range 12.0-84.0\% (Vanhaecke et al. 1990), whereas the surface hydrophobicity values of $S$. epidermidis strains were reported to range between 22.0 and $81.0 \%$ (Jones et al. 1996). In another report, the surface hydrophobicity values of S. epidermidis strains were reported to be 4.0, 7.0, 8.0, and 55.0\% (Hanlon et al. 1999).

In this study, the control E. coli ATCC 25922 strain and the test $E$. coli strain gave similar results, and similar results were observed between the control S. aureus ATCC 25923 strain and the test $S$. epidermidis strains.

\section{Static water contact angle}

The static water contact angles of the 10 selected isolates and the controls are shown in Table 3.

The surface adhesion potential of microorganisms can be evaluated by measuring the static water contact angle. In the literature, it is reported that there is a positive correlation between the static water contact angle and the ability of microorganisms to adhere to the surface (Boonaert et al. 2001; Li and Logan 2004).

When the static water contact angle values of the isolates were examined, $B$. toyonensis and $P$. aeruginosa exhibited the highest, whereas $C$. parapsilosis and $P$. mirabilis exhibited the lowest values (Table 3 ). It can be said that $B$. toyonensis and $P$. aeruginosa have the highest adhesion capability based on static water contact angle results.

The surface properties may vary on the strain basis. For example, the static water contact angle values of $P$. aeruginosa strains have been reported to be $36^{\circ}$ (Pasmore et al. 2001), between 21 and $85^{\circ}$, generally between 65 and $85^{\circ}$ (Triandafillu et al. 2003). Moreover, the static water contact angle values in present study are generally consistent with the literature for the same species (Feng et al. 2009; Hamadi and Latrache 2008; van Merode et al. 2008). Because of the lack of information in the literature about the static water contact angle values for $B$. toyonensis, the static water contact angle 
values for $B$. toyonensis were compared with those for $B$. subtilis or $B$. cereus. The static water contact angle values for $B$. subtilis have been reported as being between 33 and $59^{\circ}$, generally $40^{\circ}$, for the vegetative forms, and between 20 and $45^{\circ}$, generally $30^{\circ}$, for the spore forms (Ahimou et al. 2001). The static water contact angle value of $B$. cereus has been reported as being $25^{\circ}$ (Bernardes et al. 2010).

\section{Salt aggregation test}

The SAT values of the 10 selected isolates and the controls are shown in Table 3.

The salt aggregation test gives information about the surface adhesion of microorganisms. Cultures with SAT values of 0.01 to $0.2 \mathrm{M}$ are considered highly hydrophobic, while those of 0.2 to $1.5 \mathrm{M}$ are considered hydrophobic, and cultures with SAT values greater than $1.5 \mathrm{M}$ are considered hydrophilic (Styriak et al. 1999). Microorganisms with hydrophilic SAT values demonstrate a greater ability to adhere surfaces. Hence, B. toyonensis, P. aeruginosa, E. coli, P. mirabilis, and $C$. parapsilosis were found to be hydrophilic, L. garvieae (M17 1.1.1.) and $K$. variicola were hydrophobic, and $E$. faecalis, $S$. epidermidis, and L. garvieae (M17 13.1.2.) were highly hydrophobic. The control strains E. coli ATCC 25922 and $S$. aureus ATCC 25923 were also highly hydrophobic (Table 3). It can be said that $B$. toyonensis, P. aeruginosa, E. coli, and $P$. mirabilis have the highest adhesion capability, whereas E. faecalis, S. epidermidis, and L. garvieae (M17 1.1.1.) have the lowest adhesion based on salt aggregation test results.

The surface properties may vary even in different strains of a species. For example, the SAT values of $P$. aeruginosa strains have been reported to be within the range 0.0-4.0 M (Vanhaecke et al. 1990). The SAT values of $S$. aureus strains have been reported to be $<0.1 \mathrm{M}$ (Ljungh et al. 1985) or between 0.025-2.0 M (Ljungh and Wadström 1995). Otherwise, considering the same species, SAT results are mostly consistent with the literature (Arana et al. 1999; Marín et al. 1997). In as much as there is no information about the SAT values for B. toyonensis in the literature, they were compared with those for $B$. thuringensis, B. licheniformis, or $B$. cereus. These latter species have been reported as having SAT values of $2.0 \mathrm{M}, 1.8 \mathrm{M}$, and $0.2 \mathrm{M}$, respectively (Obuekwe et al. 2009).

\section{Surface zeta potential test}

The surface zeta potential values of the 10 selected isolates and the controls are shown in Table 3.

The surface zeta potential is used to assess the potential of microorganisms to adhere various surfaces. The value of the surface zeta potential depends on ionic strength. As the ionic strength increases, the surface zeta potential value for a microorganism increases, which causes its hydrophobicity to increase. Because of this increase in hydrophobicity, the ability of the microorganism to adhere to surfaces decreases. The surface zeta potential value is determined using the absolute value of the data. Microorganisms with small absolute surface zeta potential values have a high surface binding ability. In other words, the absolute surface zeta potential value and the ability of microorganisms to adhere to surfaces are inversely proportional (Li and Logan 2004).

When the absolute surface zeta potential values of the isolates were examined, $P$. aeruginosa and E. coli exhibited the lowest, whereas L. garvieae (M17 1.1.1. and M17 13.1.2.) and S. epidermidis exhibited the highest values (Table 3 ). It can be said that $P$. aeruginos $a$ and $E$. coli have the highest adhesion capability, whereas L. garvieae (M17 1.1.1. and M17 13.1.2.) and $S$. epidermidis have the lowest adhesion based on absolute surface zeta potential results.

Even a different strain of a species may have different surface properties. For example, the surface zeta potential values of $P$. aeruginosa strains have been reported to be -9.0 and $16.0 \mathrm{mV}$ (Gómez-Suárez et al. 2002). The surface zeta potential values of the $S$. epidermidis strains have been reported as being between -6.0 and $-10.0 \mathrm{mV}$ (Gallardo-Moreno et al. 2009). On the other hand, surface zeta potential results were obtained in accordance with the literature ( $\mathrm{Li}$ and McLandsborough 1999; Wang et al. 2012). The B. toyonensis surface zeta potential values were compared with those of $B$. subtilis or B. licheniformis because there is not any study about this. The surface zeta potential values of $B$. subtilis have been reported as being between -15.0 and $-50.0 \mathrm{mV}$ (Ahimou et al. 2001). The B. licheniformis surface zeta potential values have been reported as being between - 16.0 and $43.0 \mathrm{mV}$ (Li et al. 2009).

\section{Exopolysaccharide composition}

\section{Total sugar and uronic acid}

The total sugar and uronic acid contents of the EPS produced by the 10 selected isolates are shown in Table 4 .

In literature, the results for the total sugar of the isolates are generally consistent with those for total uronic acid content (Strathmann et al. 2002). The results of the present study were also consistent in terms of total sugar and uronic acid content. $P$. aeruginosa showed the highest sugar- and uronic acidproducing abilities followed by $S$. epidermidis. Both the $L$. garvieae isolates showed the lowest sugar-producing ability, followed by $E$. coli. However, these two L. garvieae isolates were followed by $P$. mirabilis in terms of the lowest uronic acid content. B. toyonensis showed relatively lower sugar- and uronic acid-producing abilities compared with $P$. aeruginosa.

The ability to produce EPS by a microorganism, as well as the EPS content, is thought to be major contributors to 
Table 4 Total sugar and uronic acid contents

\begin{tabular}{lllc}
\hline Isolate code & Microorganism & $\begin{array}{l}\text { Total sugar } \\
\left(\mu \mathrm{g} / 10^{9} \text { cells }\right)\end{array}$ & $\begin{array}{l}\text { Uronic acid } \\
\left(\mu \mathrm{g} / 10^{9} \text { cells }\right)\end{array}$ \\
\hline FVRBA 1.1.5. & Pseudomonas aeruginosa & 1900 & 108 \\
BPA 5.2.2. & Staphylococcus epidermidis & 1560 & 89 \\
VRBDA 1.1.1. & Proteus mirabilis & 1368 & 62 \\
FVRBA 7.1.2. & Klebsiella variicola & 1357 & 65 \\
MRS 4.2.1. & Candida parapsilosis & 1333 & 69 \\
YEA 5.2.6. & Bacillus toyonensis & 1227 & 63 \\
YEA 13.2.1. & Enterococcus faecalis & 1050 & 72 \\
VRBDA 7.1.1. & Escherichia coli & 1012 & 66 \\
M17 13.1.2. & Lactococcus garvieae & 837 & 58 \\
M17 1.1.1. & Lactococcus garvieae & 790 & 52 \\
\hline
\end{tabular}

adhesion and biofilm formation on surfaces. Uronic acid is the most abundant acidic sugar found in the EPS. Therefore, assessing the EPS production ability of the test microorganisms, and measuring the total sugar and uronic acid, may be most predictive of the ability of a microorganism to adhere surface. As mentioned earlier, P. aeruginosa and B. toyonensis exhibited the best results based on the surface tests. When these two bacteria were assessed in terms of total sugar and uronic acid in their EPS, P. aeruginosa was found to have a much better results than $B$. toyonensis.

In one study, the total carbohydrate content of $P$. aeruginosa was found to be $705-749 \mu \mathrm{g} / 10^{9}$ cells in the biofilm and $535-512 \mu \mathrm{g} / 10^{9}$ cells in the EPS. Moreover, the uronic acid content was found to be $408-450 \mu \mathrm{g} / 10^{9}$ cells in the biofilm and 354-381 $\mu \mathrm{g} / 10^{9}$ cells in the EPS (Strathmann et al. 2002). In another study, the total carbohydrate content in $P$. aeruginosa was found to be $1006 \mu \mathrm{g} / 10^{9}$ cells in the biofilm and $767 \mu \mathrm{g} / 10^{9}$ cells in the EPS. In this same study, the uronic acid content was found to be $474 \mu \mathrm{g} / 10^{9}$ cells in the biofilm and $403 \mu \mathrm{g} / 10^{9}$ cells in the EPS (Wingender et al. 2001).

\section{Neutral sugar content}

The percentage distribution of neutral sugars extracted from each isolate is shown in Table 5.

The neutral sugar content of the EPS may be an important contributing factor for adhesion of microorganisms (Yang 2000). As expected, there were large variations in the neutral sugar content in EPS produced by the different isolates (Table 5).

Glucose and mannitol were the two most abundant two neutral sugars produced by $P$. aeruginosa, with mannose and glucose being two most abundant two neutral sugars produced by $K$. varriicola, sorbitol and mannose by $P$. mirabilis, glucose and sorbitol by L. garvieae (M17 13.1.2.), glucose and mannose by $B$. toyonensis, sorbitol and glucose by $S$. epidermidis, mannose and sorbitol by L. garvieae (M17 1.1.1.), mannose and sorbitol by E. faecalis, glucose and ribose by $C$. parapsilosis, and sorbitol and mannose by $E$. coli (Table 5).

The following sugars have been demonstrated to be present in the EPS from different microorganisms: ribose, arabinose, mannose, glucose, and galactose in the EPS from the Bacillus spp. (Fox 1999); glucose, xylose, and rhamnose in the EPS from the $P$. aeruginosa (Yokota et al. 1987); glucose, galactose, and rhamnose in the EPS from the Enterococcus spp. (Mozzi et al. 2006); fucose and galactose in the EPS from the L. lactis subsp. lactis (Suzuki et al. 2013); glucose, mannose, galactose, and arabinose in the EPS from the $C$. albicans (Kiran et al. 2015); and mannose, galactose, glucose, galactonic acid, arabinose, fucose, rhamnose, and xylose in the EPS from the $S$. epidermidis and $E$. coli (Bales et al. 2013).

EPS are microbial substances that have important contributions in the formation of biofilm. EPS are critical to the maturation of the biofilm structure as well as the initial binding stage of microorganisms (Marshall 1992), (Sutherland 1982). The EPS protect the bacteria from dehydration by holding water and are drying very slowly (Ophir and Gutnick 1994), (Roberson and Firestone 1992). EPS are also important for the survival of microorganisms in adverse environmental conditions (Rinker and Kelly 1996). Moreover, the EPS are effective in keeping the nutrients for the biofilm structure to mature and protecting the cells against antimicrobial agents.

In order to eliminate microorganisms in the biofilm structure, the biocides must penetrate to the EPS structure and reach the microorganism cells which are in the inner layers (Meyer 2003). Since the EPS composition differs according to the biofilm type, different methods are used for each biofilm structure. For example, oxidation agents such as peracetic acid and chlorine are preferred for the elimination of biofilm layers formed by Pseudomonas and Listeria on stainless steel surfaces (Jang et al. 2006). Active chlorine is preferred due to its ability to remove microorganisms in the biofilm structure as well as to remove EPS on the surface (Meyer 2003). Ozone is a strong oxidizing agent and has been successfully applied to 


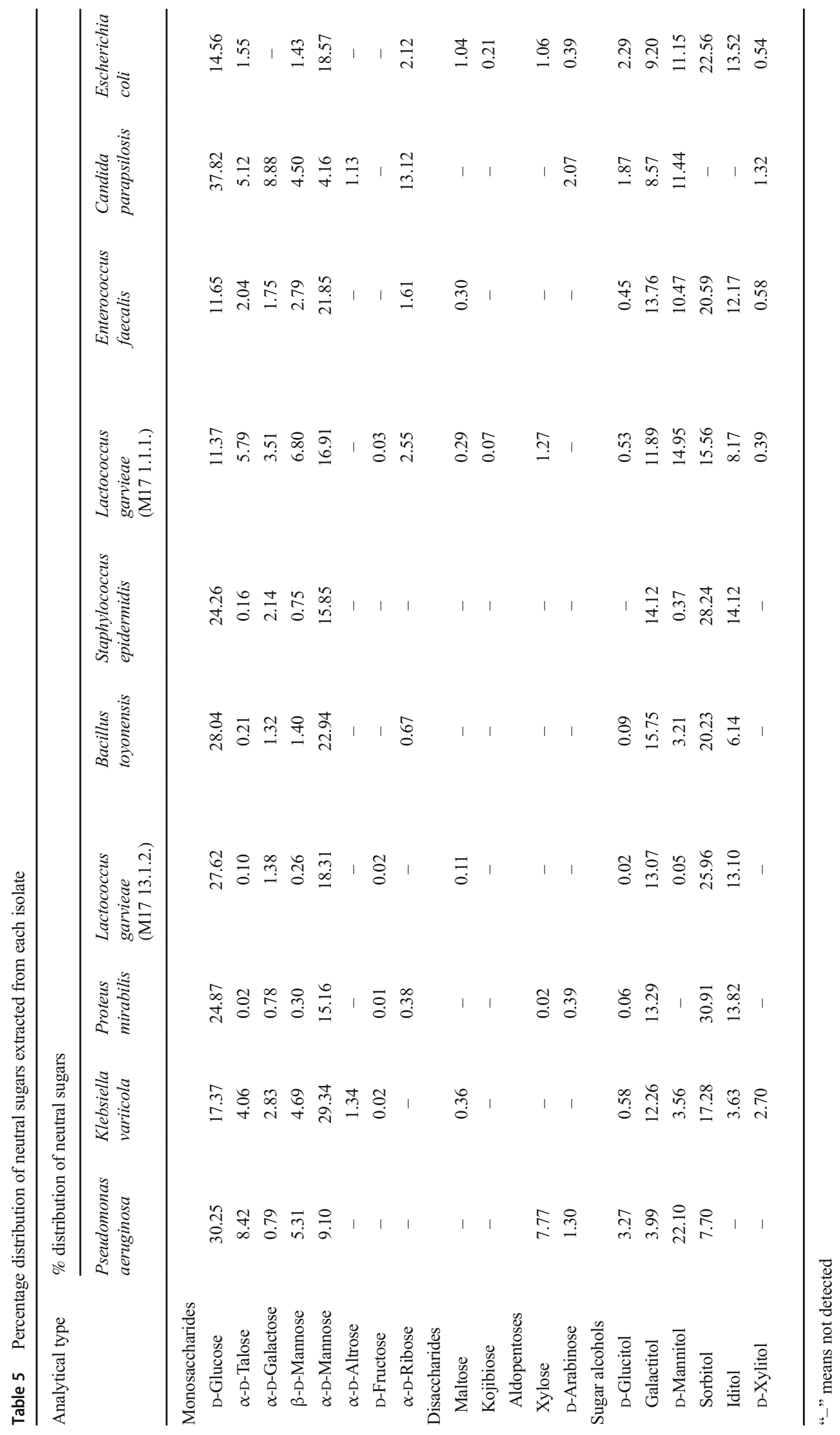


remove biofilms from oligotrophic water systems (Barnes and Caskey 2002).

Bacteriocins are also used to minimize the biofilm formation of foodborne pathogenic microorganisms. It was stated that the use of plantaricin 423, pediocin PD-1, and nisin was effective against the biofilm structure formed by Oenococcus oeni (Nel et al. 2002). Moreover, EPS also increase the resistance of microorganisms to cleaning agents. It was reported that the catalase enzyme in biofilm structure of $P$. aeruginiosa was effective in reducing the efficacy of hydrogen peroxidecontaining disinfectants (Stewart et al. 2000).

In the present study, the EPS-producing ability of surface adhesive microorganisms in a dairy plant and the content of EPS they produce were determined. The data about EPS content of the isolates shed some light on the determination of the chemicals which should be preferred for effective cleaning/ disinfection in a dairy plant.

\section{Discussion}

In this study, several microorganisms were isolated from different sampling points in a dairy plant. The microorganisms were isolated after cleaning/disinfection to a similar degree as before cleaning/disinfection of the sampling points in the dairy plant. The microorganism isolates included microorganisms that may be pathogenic or are opportunistic pathogens, or could potentially affect other microorganisms and cause a deterioration of the milk and dairy products. Some sampling points drew attention as being processing points that may cause post-production contamination.

Stainless steel is the most preferred material on the surface of the equipment and materials used in the food industry, and the hydrophilic property of these surfaces is an important factor in biofilm formation (Frank 2001). In literature, it was shown that the critical surface tension value promotes the attachment of microorganisms to various surfaces (Boulange-Petermann et al. 1993), (Bryers 1987). As the free surface energy and the wettability of the surface increase, the binding of the bacterial cells to the surface approaches the maximum level. The surfaces with high free surface energy such as stainless steel and glass are more hydrophilic. These surfaces cause higher bacterial binding and thus cause more biofilm formation compared with hydrophobic surfaces such as Teflon, nylon, and rubber (Blackman and Frank 1996), (Hyde et al. 1997), (Mafu et al. 1990), (Sinde and Carballo 2000). In a study by Smoot and Pierson (Smoot and Pierson 1998), it was noted that Listeria monocytogenes attaches faster but stronger to stainless steel surfaces than rubber surfaces.

In this study, numerous microorganisms were isolated after cleaning and disinfection of the pasteurized milk tank, yogurt filling unit, white cheese tank, ice cream filling unit, ice cream air pressing pipe, butter tank, and condensed milk pipe. All these units came into direct contact with the final dairy product. This is important in terms of food hygiene and food quality, so further precautions should be taken in this particular dairy plant.

API test kits and 16S rRNA gene sequencing results were consistent at the genus level, but there were some differences at the species level. The species level identification was most consistent for Staphylococcus but varied significantly for lactic acid bacteria and yeasts.

Within the scope of this study, the surface properties of 10 selected isolates were determined to assess their ability for surface adhesion. Among the surface tests, the MATH test exhibited the lowest standard deviations, and the most consistent results between the replicates. It can be said that, MATH test is the most useful test in determining the surface properties of microorganisms with respect to surface adhesion. The hydrophilic character of microorganisms provides higher surface adhesion potential. $P$. aeruginosa, a Gram-negative isolate, and $B$. toyonensis, a Grampositive isolate, exhibited the best results in terms of surface test. The ability of the test bacteria to produce exopolysaccharides, which are a major contributor to adhesion, is thought to be related more to biofilm formation on the surface than on the cell's ability to adhere to the surface. In addition, the total sugar and uronic acid content have great importance during the assessment of surface adhesion. When the exopolysaccharides from these two bacteria were assessed in terms of total sugar and uronic acid, $P$. aeruginosa was indicated to have better results than $B$. toyonensis. Moreover, neutral sugar was determined in their alditol acetate forms by using gas chromatography-mass spectrometry. A wide variety of neutral sugar content was determined for each of the isolates. P. aeruginosa had richer neutral sugar content in its exopolysaccharide than that of B. toyonensis. As a result, it is believed that determination of the EPS content would contribute to establishing of the effective cleaning/disinfection procedure for dairy plants.

In the next step of the study, the biofilm formation will be investigated with these two test bacteria ( $P$. aeruginosa and $B$. toyonensis) by using stainless steel plates in batch and flow growth media.

Funding information This work was supported by the Hacettepe University Scientific Research Projects Coordination Unit (Project Codes: 014 D01 602003 and FDK-2016-13096).

\section{Compliance with ethical standards}

Conflict of interest The authors declare that they have no conflict of interest.

Research involving human participants and/or animals This article does not contain any studies with human participants or animals performed by any of the authors.

Informed consent Not applicable. 


\section{References}

Abasolo-Pacheco F, Saucedo PE, Mazon-Suastegui JM et al (2015) Isolation and use of beneficial microbiota from the digestive tract of lions-paw scallop Nodipecten subnodosus and winged pearl oyster Pteria sterna in oyster aquaculture. Aquac Res:1-10. https://doi. org/10.1111/are.12754

Absolom DR, Lamberti FV, Policova Z et al (1983) Surface thermodynamics of bacterial adhesion. Appl Environ Microbiol 46:90-97

Ahimou F, Paquot M, Jacques P et al (2001) Influence of electrical properties on the evaluation of the surface hydrophobicity of Bacillus subtilis. J Microbiol Methods 45:119-126. https://doi.org/10.1016/ S0167-7012(01)00240-8

Arana I, Santorum P, Muela A, Barcina I (1999) Chlorination and ozonation of waste-water: comparative analysis of efficacy through the effect on Escherichia coli membranes. J Appl Microbiol 86:883888

Bağc1 U (2012) Determination of some important properties of lactic acid bacteria isolated from human milk based on food technology. Dissertation, Hacettepe University, Graduate School of Science and Engineering

Bales PM, Renke EM, May SL et al (2013) Purification and characterization of biofilm-associated EPS exopolysaccharides from ESKAPE organisms and other pathogens. PLoS One 8:1-8. https://doi.org/10.1371/journal.pone.0067950

Barnes RL, Caskey DK (2002) Using ozone in the prevention of bacterial biofilm formation and scaling. In: Water cond purification, technical report. October, vol 44, pp 1-3

Bernardes PC, de Andrade NJ, Ferreira SO et al (2010) Assessment of hydrophobicity and roughness of stainless steel adhered by an isolate of Bacillus cereus from a dairy plant. Brazilian J Microbiol 41: 984-992. https://doi.org/10.1590/S1517-83822010000400017

Bjerkan G, Witsø E, Bergh K (2009) Sonication is superior to scraping for retrieval of bacteria in biofilm on titanium and steel surfaces in vitro. Acta Orthop 80:245-250. https://doi.org/10.3109/ 17453670902947457

Blackman IC, Frank JF (1996) Growth of Listeria monocytogenesas a biofilm on various food-processing surfaces. J Food Prot 59:827831

Blumenkrantz N, Asboe-Hansen G (1973) New method for quantitative determination of uronic acids. Anal Biochem 54:484 489. https:// doi.org/10.1016/0003-2697(73)90377-1

Boonaert CJP, Dufrêne YF, Derclaye SR, Rouxhet PG (2001) Adhesion of Lactococcus lactis to model substrata: direct study of the interface. Colloids Surf B Biointerfaces 22:171-182. https://doi.org/10. 1016/S0927-7765(01)00196-5

Boulange-Petermann L, Baroux B, Bellon-Fontaine M-N (1993) The influence of metallic surface wettability on bacterial adhesion. $\mathrm{J}$ Adhes Sci Technol 7:221-230. https://doi.org/10.1163/ $156856193 \times 00673$

Brolazo EM, Leite DS, Tiba MR et al (2011) Correlation between api 50 ch and multiplex polymerase chain reaction for the identification of vaginal lactobacilli in isolates. Brazilian J Microbiol 42:225-232. https://doi.org/10.1590/S1517-83822011000100028

Bryers JD (1987) Biologically active surfaces: processes governing the formation and persistence of biofilms. Biotechnol Prog 3:57-68. https://doi.org/10.1002/btpr.5420030202

Chen X, Stewart PS (2002) Role of electrostatic interactions in cohesion of bacterial biofilms. Appl Microbiol Biotechnol 59:718-720. https://doi.org/10.1007/s00253-002-1044-2

Cherif-Antar A, Moussa-Boudjemâa B, Didouh N et al (2016) Diversity and biofilm-forming capability of bacteria recovered from stainless steel pipes of a milk-processing dairy plant. Dairy Sci Technol 96: 27-38. https://doi.org/10.1007/s13594-015-0235-4
Donlan RM, Costerton JW (2002) Biofilms: survival mechanisms of clinically relevant microorganisms. Clin Microbiol 15:167-193. https://doi.org/10.1128/CMR.15.2.167

Drenkard E (2003) Antimicrobial resistance of Pseudomonas aeruginosa biofilms. Microbes Infect 5:1213-1219. https://doi.org/10.1016/j. micinf.2003.08.009

DuBois M, Gilles KA, Hamilton JK et al (1956) Colorimetric method for determination of sugars and related substances. Anal Chem 28:350 356. https://doi.org/10.1021/ac60111a017

Feng L, Li X, Du G, Chen J (2009) Adsorption and fouling characterization of Klebsiella oxytoca to microfiltration membranes. Process Biochem 44:1289-1292. https://doi.org/10.1016/j.procbio.2009.07. 017

Fox A (1999) Carbohydrate profiling of bacteria by gas chromatography - mass spectrometry and their trace detection in complex matrices by gas chromatography - tandem mass spectrometry. J Chromatogr A 843:287-300

Frank JF (2001) Microbial attachment to food and food contact surfaces. Adv Food Nutr Res 43:319-370. https://doi.org/10.1016/S10434526(01)43008-7

Frank JF, Koffi RA (1990) Surface adherence growth of Listeria monocytogenes is associated with increased resistance to surfactant sanitizers and heat. J Food Prot 53:550-554

Gallardo-Moreno AM, Pacha-Olivenza MA, Saldana L et al (2009) In vitro biocompatibility and bacterial adhesion of physicochemically modified Ti6Al4V surface by means of UV irradiation. Acta Biomater 5:181-192. https://doi.org/10.1016/j.actbio.2008.07. 028

Gómez-Suárez C, Pasma J, van der Borden AJ et al (2002) Influence of extracellular polymeric substances on deposition and redeposition of Pseudomonas aeruginosa to surfaces. Microbiology 148:11611169. https://doi.org/10.1099/00221287-148-4-1161

Hamadi F, Latrache H (2008) Comparison of contact angle measurement and microbial adhesion to solvents for assaying electron donor electron acceptor (acid - base) properties of bacterial surface. Colloids Surf B Biointerfaces 65:134-139. https://doi.org/10.1016/ j.colsurfb.2008.03.010

Hanlon GW, Olliff CJ, Brant JA, Denyer SP (1999) A novel imageanalysis technique for measurement of bacterial cell surface tension. J Pharm Pharmacol 51:207-214

Harrigan WF (1998) Laboratory methods in food microbiology. Academic Press, San Diego

Hyde FW, Alberg M, Smith K (1997) Comparison of fluorinated polymers against stainless steel, glass and polypropylene in microbial biofilm adherence and removal. J Ind Microbiol Biotechnol 19: 142-149. https://doi.org/10.1038/sj.jim.2900448

Jang A, Szabo J, Hosni AA et al (2006) Measurement of chlorine dioxide penetration in dairy process pipe biofilms during disinfection. Appl Microbiol Biotechnol 72:368-376. https://doi.org/10.1007/s00253005-0274-5

Jones DS, Adair CG, Mawhinney WM, Gorman SP (1996) Standardisation and comparison of methods employed for microbial cell surface hydrophobicity and charge determination. Int J Pharm 131:83-89. https://doi.org/10.1016/0378-5173(95)04368-3

Kajiyama S, Tsurumoto T, Osaki M et al (2009) Quantitative analysis of Staphylococcus epidermidis biofilm on the surface of biomaterial. J Orthop Sci 14:769-775. https://doi.org/10. 1007/s00776-009-1405-0

Kiran GS, Priyadharshini S, Anitha K et al (2015) Characterization of an exopolysaccharide from probiont Enterobacter faecalis MSI12 and its effect on the disruption of Candida albicans biofilm. RSC Adv 5: 71573-71585. https://doi.org/10.1039/C5RA10302A

Knight GC, Craven HM (2010) A model system for evaluating surface disinfection in dairy factory environments. Int J Food Microbiol 137:161-167. https://doi.org/10.1016/j.ijfoodmicro.2009.11.028 
Kwaszewska AK, Brewczyńska A, Szewczyk EM (2006) Hydrophobicity and biofilm formation of lipophilic skin corynebacteria. Polish J Microbiol 55:189-193

Li B, Logan BE (2004) Bacterial adhesion to glass and metal-oxide surfaces. Colloids Surf B: Biointerfaces 36:81-90. https://doi.org/10. 1016/j.colsurfb.2004.05.006

Li J, McLandsborough LA (1999) The effects of the surface charge and hydrophobicity of Escherichia coli on its adhesion to beef muscle. Int J Food Microbiol 53:185-193. https://doi.org/10.1016/S01681605(99)00159-2

Li Z, Zhong S, Lei H et al (2009) Production of a novel bioflocculant by Bacillus licheniformis X14 and its application to low temperature drinking water treatment. Bioresour Technol 100:3650-3656. https://doi.org/10.1016/j.biortech.2009.02.029

Ljungh A, Wadström T (1995) Growth conditions influence expression of cell surface hydrophobicity of staphylococci and other wound infection pathogens. Microbiol Immunol 39:753-757

Ljungh A, Hjerten S, Wadstrom T (1985) High surface hydrophobicity of autoaggregating Staphylococcus aureus strains isolated from human infections studied with the salt aggregation test. Infect Immun 47: $522-526$

Lortal S, Di Blasi A, Madec MN et al (2009) Tina wooden vat biofilm: a safe and highly efficient lactic acid bacteria delivering system in PDO Ragusano cheese making. Int J Food Microbiol 132:1-8. https://doi.org/10.1016/j.ijfoodmicro.2009.02.026

Mafu AA, Roy D, Goulet J, Hagny P (1990) Attachment of Listeria monocytogenes to stainless steel, glass, polypropylene and rubber surfaces after short contact times. J Food Prot 53:742-746

Marín ML, Benito Y, Pin C et al (1997) Lactic acid bacteria: hydrophobicity and strength of attachment to meat surfaces. Lett Appl Microbiol 24:14-18

Marques SC, Rezende JDGOS, Alves LADF et al (2007) Formation of biofilms by Staphylococcus aureus on stainless steel and glass surfaces and its resistance to some selected chemical sanitizers. Brazilian J Microbiol 38:538-543. https://doi.org/10.1590/S151783822007000300029

Marshall KC (1992) Biofilms: an overview of bacterial adhesion activity and control at surfaces. Am Soc Microbiol 58:202-207

Martín R, Olivares M, Pérez M et al (2010) Identification and evaluation of the probiotic potential of lactobacilli isolated from canine milk. Vet J 185:193-198. https://doi.org/10.1016/j.tvj1.2009.04.014

Meyer B (2003) Approaches to prevention, removal and killing of biofilms. Int Biodeterior Biodegrad 51:249-253. https://doi.org/10. 1016/S0964-8305(03)00047-7

Minagi S, Miyake Y, Yumi F et al (1986) Cell-surface hydrophobicity of Candida species as determined by the contact-angle and hydrocarbon-adherence methods. J Gen Microbiol 132:1111-1115

Mozzi F, Vaningelgem F, Hebert ME et al (2006) Diversity of heteropolysaccharide-producing lactic acid bacterium strains and their biopolymers. Appl Environ Microbiol 72:4431-4435. https:// doi.org/10.1128/AEM.02780-05

Mustapha A, Liewen MB (1989) Destruction of Listeria monocytogenes by sodium hypochlorite and quaternary ammonium sanitizers. $\mathrm{J}$ Food Prot 52:306-311

Nel HA, Bauer R, Wolfaardt GM, Dicks LMT (2002) Effect of bacteriocins pediocin PD-1, plantaricin 423, and nisin on biofilms of Oenococcus oeni on a stainless steel surface. Am J Enol Vitic 53: 191-196

Obuekwe CO, Al-Jadi ZK, Al-Saleh ES (2009) Hydrocarbon degradation in relation to cell-surface hydrophobicity among bacterial hydrocarbon degraders from petroleum-contaminated Kuwait desert environment. Int Biodeterior Biodegrad 63:273-279. https://doi.org/10. 1016/j.ibiod.2008.10.004

Ophir T, Gutnick DL (1994) A role for exopolysaccharides in the protection of microorganisms from desiccation. Appl Environ Microbiol 60:740-745
Palmer JS, Flint SH, Schmid J, Brooks JD (2010) The role of surface charge and hydrophobicity in the attachment of Anoxybacillus flavithermus isolated from milk powder. J Ind Microbiol Biotechnol 37:1111-1119. https://doi.org/10.1007/s10295-0100758-x

Pasmore M, Todd P, Smith S et al (2001) Effects of ultrafiltration membrane surface properties on Pseudomonas aeruginosa biofilm initiation for the purpose of reducing biofouling. J Memb Sci 194:1532. https://doi.org/10.1016/S0376-7388(01)00468-9

Rijnaarts HHM, Norde W, Bouwer EJ et al (1995) Reversibility and mechanism of bacterial adhesion. Colloids Surf B Biointerfaces 4: 5-22. https://doi.org/10.1016/0927-7765(94)01146-V

Rinker KD, Kelly RM (1996) Growth physiology of the hyperthermophilic archaeon Thermococcus litoralis: development of a sulfurfree defined medium, characterization of an exopolysaccharide, and evidence of biofilm formation. Appl Environ Microbiol 62: $4478-4485$

Roberson EB, Firestone MK (1992) Relationship between desiccation and exopolysaccharide production in a soil Pseudomonas sp. Appl Environ Microbiol 58:1284-1291

Rosenberg M, Gutnick D, Rosenberg E (1980) Adherence of bacteria to hydrocarbons: a simple method for measuring cell-surface hydrophobicity. FEMS Microbiol Lett 9:29-33. https://doi.org/10.1017/ CBO9781107415324.004

Saini G (2010) Bacterial hydrophobicity: assessment techniques, applications and extension to colloids. Dissertation, Oregon State University, Chemical Engineering

Sanger F, Nicklen S, Coulson AR (1977) DNA sequencing with chainterminating inhibitors. Proc Nati Acad Sci USA 74:5463-5467

Sassaki GL, Souza LM, Serrato RV et al (2008) Application of acetate derivatives for gas chromatography-mass spectrometry: novel approaches on carbohydrates, lipids and amino acids analysis. J Chromatogr A 1208:215-222. https://doi.org/10.1016/j.chroma. 2008.08.083

Sinde E, Carballo J (2000) Attachment of Salmonella spp. and Listeria monocytogenes to stainless steel, rubber and polytetrafluorethylene: the influence of free energy and the effect of commercial sanitizers. Food Microbiol 17:439-447. https://doi.org/10.1006/fmic.2000. 0339

Smoot LM, Pierson MD (1998) Effect of environmental stress on the ability of Listeria monocytogenes Scott a to food contact surfaces. J Food Prot 61:1293-1298

Soares JC, Marques MR, Tavaria FK et al (2011) Biodiversity and characterization of Staphylococcus species isolated from a small manufacturing dairy plant in Portugal. Int J Food Microbiol 146: 123-129. https://doi.org/10.1016/j.ijfoodmicro.2011.02.008

Stewart PS, Roe F, Rayner J et al (2000) Effect of catalase on hydrogen peroxide penetration into Pseudomonas aeruginosa biofilms. Appl Environ Microbiol 66:836-838. https://doi.org/10.1128/AEM.66.2. 836-838.2000

Strathmann M, Wingender J, Flemming HC (2002) Application of fluorescently labelled lectins for the visualization and biochemical characterization of polysaccharides in biofilms of Pseudomonas aeruginosa. J Microbiol Methods 50:237-248. https://doi.org/10. 1016/S0167-7012(02)00032-5

Styriak I, Laukova A, Fallgren C, Wadström T (1999) Binding of selected extracellular matrix proteins to enterococci and Streptococcus bovis of animal origin. Curr Microbiol 39:327-335. https://doi.org/10. $1007 / \mathrm{s} 002849900467$

Sutherland IW (1982) Microbial exopolysaccharides - their role in microbial adhesion in aqueous systems. Crit Rev Microbiol 10:173-201. https://doi.org/10.3109/10408418209113562

Suzuki C, Kobayashi M, Kimoto-nira H (2013) Novel exopolysaccharides produced by Lactococcus lactis subsp. lactis, and the diversity of epsE genes in the exopolysaccharide 
biosynthesis gene clusters. Biosci Biotechnol Biochem 77:20132018. https://doi.org/10.1271/bbb.130322

Tang L, Pillai S, Revsbech NP et al (2011) Biofilm retention on surfaces with variable roughness and hydrophobicity. Biofouling 27:111121. https://doi.org/10.1080/08927014.2010.544848

Temiz A (2010) Genel Mikrobiyoloji Uygulama Teknikleri. Hatipoğlu Yayınları, Ankara

Triandafillu K, Balazs DJ, Aronsson BO et al (2003) Adhesion of Pseudomonas aeruginosa strains to untreated and oxygen-plasma treated poly(vinyl chloride) (PVC) from endotracheal intubation devices. Biomaterials 24:1507-1518. https://doi.org/10.1016/S01429612(02)00515-X

Ukuku DO, Fett WF (2002) Relationship of cell surface charge and hydrophobicity to strength of attachment of bacteria to cantaloupe rind. J Food Prot 65:1093-1099

Valeriano C, de Oliveira TLC, de Carvalho SM et al (2012) The sanitizing action of essential oil-based solutions against Salmonella enterica serotype Enteritidis S64 biofilm formation on AISI 304 stainless steel. Food Control 25:673-677. https://doi.org/10.1016/j. foodcont.2011.12.015

van Merode AEJ, Duval JFL, van der Mei HC et al (2008) Increased adhesion of Enterococcus faecalis strains with bimodal electrophoretic mobility distributions. Colloids Surf B Biointerfaces 64:302306. https://doi.org/10.1016/j.colsurfb.2008.02.004

Vanhaecke E, Remon J, Moors M et al (1990) Kinetics of Pseudomonas aeruginosa adhesion to 304 and 316-L stainless steel: role of cell surface hydrophobicity. Appl Environ Microbiol 56:788-795
Waines PL, Moate R, Moody AJ et al (2011) The effect of material choice on biofilm formation in a model warm water distribution system. Biofouling 27:1161-1174. https://doi.org/10.1080/08927014.2011. 636807

Wang SY, Chen KN, Lo YM et al (2012) Investigation of microorganisms involved in biosynthesis of the kefir grain. Food Microbiol 32:274 285. https://doi.org/10.1016/j.fm.2012.07.001

Watnick P, Kolter R (2000) Biofilm, city of microbes. J Bacteriol 182: 2675-2679. https://doi.org/10.1128/JB.182.10.2675-2679.2000

Wingender J, Strathmann M, Rode A et al (2001) Isolation and biochemical characterization of extracellular polymeric substances from Pseudomonas aeruginosa. Methods Enzymol 336:302-314

Yang Z (2000) Antimicrobial compounds and extracellular polysaccharides produced by lactic acid bacteria: structures and properties. Dissertation, University of Helsinki, Department of Food Technology

Yokota S, Kaya S, Sawada S et al (1987) Characterization of a polysaccharide component of lipopolysaccharide from Pseudomonas aeruginosa IID 1008 (ATCC 27584) as D-rhamnan. Eur J Biochem 209:203-209

Publisher's note Springer Nature remains neutral with regard to jurisdictional claims in published maps and institutional affiliations. 